\title{
POTENTIAL ROLE OF WILD CRUCIFERS IN THE PRESERVATION OF DIADEGMA EUCEROPHAGA HORSTMAN (HYMENOPTERA: ICHNEUMONIDAE), A PARASITOID OF THE DIAMONDBACK MOTH, PLUTELLA XYLOSTELLA LINNAEUS (LEPIDOPTERA: PLUTELLIDAE)
}

\author{
UTOMO KARTOSUWONDO \\ Faculty of Agriculture \\ Bogor Agricultural University \\ Bogor, Indonesia \\ SUNJAYA \\ Tropical Agricultural Pest Biology Programme, SEAMEO BIOTROP Bogor, \\ Indonesia
}

\begin{abstract}
Laboratory and field experiments were conducted to evaluate the potential role of two species of wild crucifers in the preservation of Diadegma eucerophaga Horstman, a parasitoid of the diamondback moth, Plutella xylostella Linnaeus. In the laboratory, D. eucerophaga developed quite well on $P$. xylostella larvae fed on leaves of two species of wild cruciferous plants, Nasturtium heterophyllum BL. and Cardamine hirsuta L. These wild crucifers may serve as food and oviposition sites for P. xylostella. In the field, N. heterophyllum and C. hirsuta planted adjacent to insecticide-treated cabbage plots provided refuge for D. eucerophaga parasitoids.
\end{abstract}

\section{INTRODUCTION}

The diamondback moth, Plutella xylostella Linnaeus, is a major pest of cole crops in Indonesia (and other parts of the world). In Indonesia, an introduced parasitoid, Diadegma eucerophaga Horstman, plays an important role as a natural control agent of diamondback moths. The parasitoid was established in the cabbage-growing regions in West Java where the rate of parasitism was reported to be in the range of 5-86\% (Sudarwohadi 1984).

In the absence of insecticide application, D. eucerophaga parasitoids can often give an effective natural control of the diamondback moth. Since insecticides are regularly applied to cabbage fields, the role of D. eucerophaga in suppressing diamondback moth population may be severely affected by intensive insecticide applications. Under such unfavourable condition, a sound ecological measure should be undertaken in order to preserve D. eucerophaga parasitoids.

Preservation of natural enemies can be achieved, among other means, through the provision of refuge for natural enemies by managing wild host plants growing 
in the surrounding of the main-crop field. Preservation of natural enemies through appropriate management of wild host plants is a feasible means which can be incorporated in any crop pest management (van Emden 1976).

Wild alternative host plants growing in the vicinity of the main-crop field can enhance the survival of a limited number of pest individuals and its natural enemies in the absence of the main host plant (Ullyett 1947 in van den Bosch and Telford 1973). It has been known that a number of wild cruciferous plant species can serve as alternative hosts for P. xylostella (Harcourt 1957). These wild crucifers may serve as refugium for the $D$. eucerophaga parasitoids when the main crop is being treated with insecticides or during a fallow period, provided that the parasitoid can develop on diamondback moth larvae feeding on wild crucifers.

Preservation of natural enemies is an important component of pest management programme (Luckmann and Metcalf 1975). Natural enemies can be affected by insecticide application in two ways: they die of insecticide intoxication or due to lack of food (hosts or preys) which are eliminated by insecticides. In order to assure the availability of food for natural enemies, it is necessary to adopt a control approach that will leave a pest residue, below its economic threshold. In the case of the diamondback moth, the pest residue may find refuge in the wild cruciferous plants growing in the surrounding of the main-crop field and in turn, the diamondback moth residue can support the development and survival of $D$. eucerophaga parasitoids.

In Java, it was reported that $P$. xylostella can live on the following cruciferous plants: Capsellabursa-pastoris, Cardamine hirsuta (Everaarts 1981) and Nasturtium heterophyllum (Backer and van Slooten 1924). The potential role of the last two wild crucifers, which can be found in Bogor and Pacet highland, West Java, in the preservation of $D$. eucerophaga parasitoids was evaluated in this study.

Laboratory and field experiments were carried out to study: 1) the oviposition preference of the diamondback moth to $N$. heterophyllum, $C$. hirsuta and cabbage, 2) the development of the diamondback moth on $N$. heterophyllum and C. hirsuta, 3) the development and survival of $D$. eucerophaga parasitoids on diamondback moth larvae fed on leaves of $N$. heterophyllum and C. hirsuta, and 4) the occurrence of D. eucerophaga on $N$. heterophyllum and $C$. hirsuta planted adjacent to cabbage plots.

\section{MATERIALS AND METHODS}

Laboratory experiments were carried out in the Tropical Pest Laboratory, SEAMEO BIOTROP, Bogor, from November 1988 to February 1989, while field 
experiments were conducted in the horticultural experimental farm, Segunung, Facet, from January to April 1989.

\section{Insects and Food Plants}

Larvae, pupae and adults of the diamondback moth were collected from cabbage fields around Facet (1100 $\mathrm{m}$ in altitude), Cianjur, West Java. Insects were maintained in the laboratory on Brassica juncea. D. eucerophaga parasitoids were collected from the same area as diamondback moth and reared in the laboratory on diamondback moth larvae. Both adults, $P$. xylostella and D. eucerophaga were fed on $10 \%$ honey solution soaked in cotton wool.

Experimental host plants, cabbage (Brassica oleracea var. capitata), Nasturtium heterophyllum and Cardamine hirsuta, were planted in an insecticide-free area in a green house at SEAMEO BIOTROP, Bogor. When used, the age of plants was about 40-60 days old.

\section{Experiments}

The study consisted of three laboratory experiments (1-3) and two field experiments (4-5). The first three experiments served as a preliminary study for the last two.

\section{Experiment 1}

Oviposition preference of the diamondback moth to $N$. heterophyllum, C. hirsute and Brassica oleracea var. capitata

$N$. heterophyllum, C. hirsuta and cabbage plants kept separately on small vials containing water were placed in a wooden-framed muslin cloth cage $(30 \times 30 \times 30 \mathrm{~cm})$. A pair of mated diamondback moth adults was then introduced into the cage. The number of eggs deposited by the female on the three plant species was recorded daily until the female died. Food plants were replaced daily. Each treatment (plant species) was replicated eight times and the experiment was arranged in a completely randomized design.

\section{Experiment 2}

Development of the diamondback moth on $N$. heterophyllum, C. hirsuta and Brassica oleracea var. capitata

Eggs deposited by diamondback moth females maintained in cages containing larval food plants were transferred separately into a plastic cage $(15 \mathrm{~cm}$ in diameter and $20 \mathrm{~cm}$ high) containing the corresponding food plants. Food plants were replaced daily. Insect development was followed until adult emergence, and the duration of 
the egg, larval and pupal development stages were recorded. The experimental design was the same as in Experiment 1.

\section{Experiment 3}

Survival of $D$. eucerophaga on diamondback moth larvae fed on leaves of $N$. heterophyllum and $C$. hirsuta

Ten third-instar diamondback moth larvae were confined in a plastic cage $(25 \mathrm{~cm}$ in diameter and $50 \mathrm{~cm}$ high) containing $N$. heterophyllum or C. hirsuta plants as food. A pair of mated adult of $D$. eucerophaga parasitoids was then released into the cage. The female parasitoid was allowed to oviposit on diamondback moth larvae for five hours and then the parasitoid pair were removed from the cage. The number of parasitoid adults emerged from parasitized diamondback moth larvae was recorded. The percentage of emergence was calculated based on the number of diamondback moth larvae used. The experiment was arranged in a completely randomized design with two treatments (two species of wild crucifers) and eight replications.

\section{Experiment 4}

Occurrence of $D$. eucerophaga on $N$. heterophyllum, C. hirsuta and B. oleracea var. capitata in the field

$N$. heterophyllum, $C$. hirsuta, and cabbage plants were planted separately on thirty field small plots (1x1 m) which were divided into ten blocks. Thus, each block consisted of three small plots containing the three plant species (one species/plot). Plants were not treated with insecticides. The experimental plots were examined regularly for evidence of diamondback moth infestation. Infested plant leaves (containing diamondback moth larvae) were removed and transferred to plastic cages $(25 \mathrm{~cm}$ in diameter and $50 \mathrm{~cm}$ high) in the laboratory. Collected diamondback moth larvae were fed on the same food plants as their origin and food plants were replaced daily. Diamondback moth larvae were examined for evidence of parasitization and the number of adult $D$. eucerophaga parasitoids which emerged was recorded. A randomized block design was used to arrange this experiment.

\section{Experiment 5}

Occurrence of D. eucerophaga on $N$. heterophyllum, C. hirsuta and insecticide treated B. oleracea var. capitata in the field

This experiment was similar to Experiment 4, but in this experiment cabbage plots were treated with Baythroid $50 \mathrm{EC}$ at a rate of $0.4 \mathrm{~kg}$ a.i./ha for each application. At the time of sampling of infested plant leaves, cabbage plots had been treated with the insecticide four times. The experimental design and the parameter observed were the same as in Experiment 4. 
Potential role of wild crucifers in the preservation of D. eucerophaga Horst. - U. Kartosuwondo \& Sunjaya

\section{RESULTS AND DISCUSSION}

\section{Oviposition preference of the diamondback moth to $N$. heterophyllum, C. hirsuta and Brassica oleracea var. capitata}

The average number of eggs deposited by the female diamondback moth per day over a seven-day oviposition period on two wild crucifers and cabbage is presented in Table 1.

Table 1. Average number of eggs deposited by the female diamondback moth on three cruciferous plant species over a seven-day oviposition period

\begin{tabular}{llllllll}
\hline \hline & \multicolumn{7}{c}{ Day } \\
\cline { 2 - 8 } Plants & 1 & 2 & 3 & 4 & 5 & 6 & 7 \\
\hline N. heterophyllum & $11.2^{1)}$ & 2.50 & 2.75 & 0.75 & 0.25 & 0.12 & 0 \\
C. hirsuta & 16.7 & 9.12 & 3.62 & 6.87 & 2.25 & 1.75 & 1.87 \\
B. oleracea & 25.6 & 10.60 & 11.20 & 4.25 & 2.00 & 0.12 & 0 \\
\hline
\end{tabular}

${ }^{1)}$ Each value in the table is an average of eight replications.

The number of eggs deposited on day-1 was the highest among the seven-day oviposition period. This result is in agreement with that obtained by Vos (1953). The oviposition preference of diamondback moth females to three cruciferous plant species is shown in Table 2.

Table 2. Average number of eggs deposited by the diamondback female on three cruciferous plant species

\begin{tabular}{lcc}
\hline \hline Food plants & $\begin{array}{c}\text { Egg plus } \\
\text { larval period }\end{array}$ & Pupal period \\
\hline$N$. heterophyllum & 11.0 a & $4.75 \mathrm{~b}$ \\
C. hirsuta & $10.38 \mathrm{a}$ & $3.0 \mathrm{c}$ \\
B. oleracea & $11.0 \mathrm{a}$ & $4.0 \mathrm{~b}$ \\
1) Means in the same column followed by a common letter were not significantly different $(\mathrm{P}=0.05)$, using \\
Least Significant Difference test; data were transformed to $\sqrt{\mathrm{X}+1}$ before analysis; each value in the table is an \\
average of eight replications.
\end{tabular}

In the laboratory, the three cruciferous plant species could serve as oviposition sites for diamondback moth females, with the order of preference: cabbage $>C$. hirsuta $>N$. heterophyllum. Apparently, the three plant species contain secondary compound(s) that act as oviposition stimulant for diamondback moths, although 
it may not be in the same amount. In crucifers, a compound that stimulates ovi-position in diamondback moths is known as mustard oil glucoside (Gupta and Thor-steinson 1960; Harborne 1988).

\section{Development of the diamondback moth on TV. heterophyllum, C. hirsuta and Brassica oleracea var. capitata}

It was known from Experiment 1 that diamondback moth females could lay eggs on the two wild crucifers tested, especially on $C$. hirsuta. Results of Experiment 2 indicated that the diamondback moth developed quite well on those wild crucifers. Egg plus larval and pupal periods of the diamondback moth reared on three cruciferous plant species are indicated in Table 3.

Table 3. Average egg plus larval and pupal periods (days) of the diamondback moth reared on three cruciferous plant species

\begin{tabular}{lcc}
\hline \hline Food plants & $\begin{array}{c}\text { Egg plus } \\
\text { larval period }\end{array}$ & Pupal period \\
\hline N. heterophyllum & $11.0 \mathrm{a}$ & $4.75 \mathrm{~b}$ \\
C. hirsuta & $10.38 \mathrm{a}$ & $3.0 \mathrm{c}$ \\
B. oleracea & $11.0 \mathrm{a}$ & $4.0 \mathrm{~b}$ \\
\hline${ }^{1)}$ Means in the same column followed by a common letter were not significantly different $(\mathrm{P}=0.05)$, using \\
Least Significant Difference test; each value in the table is an average of eight replications.
\end{tabular}

The three host plants did not affect the combined duration of egg and larval stages of the diamondback moth significantly. The effect of host plants on the diamondback moth development was manifested in the duration of the pupal stage. The pupal period of the diamondback moth maintained on $N$. heterophyllum was comparable with that on cabbage, whereas on $C$. hirsuta the pupal period was the shortest. The obtained data suggest that the nutritional contents of the three cruciferous plant species can adequately support the growth and development of the diamondback moth. Like in oviposition, a secondary compound mustard oil glucoside can also act as feeding stimulant for diamondback moth larvae (Gupta and Thorsteinson 1960; Harborne 1988).

\section{Survival of $D$. eucerophaga on diamondback moth larvae fed on leaves of TV. heterophyllum and $C$. hirsuta}

Results of Experiment 2 showed that diamondback moth larvae developed quite well on two wild crucifers, $N$. heterophyllum and $C$. hirsuta. From this experiment it can be inferred that diamondback moth larvae feeding on those wild 
crucifers could support the development of its parasitoid, D. eucerophaga. The percentage of emergence of adult parasitoids resulting from a five-hour exposure often third-instar diamondback moth larvae to a mated parasitoid pair is presented in Table 4.

The data indicated that $D$. eucerophaga could survive on diamondback moth larvae feeding on wild cruciferous plants. The yield of food plants of diamondback moth larvae did not show a significant effect on the percentage of emergence of adult parasitoids. The percentage of emergence could be higher if the female parasitoid was allowed to oviposit on its host for more than five hours.

Table 4. Average percentage of emergence of $D$. eucerophaga adults from diamondback larvae reared on two species of wild crucifers

\begin{tabular}{lc}
\hline \hline $\begin{array}{l}\text { Food plants of } \\
\text { diamondback larvae }\end{array}$ & $\begin{array}{c}\text { Percentage of emergence } \\
\text { of parasitoid adults }{ }^{1)}\end{array}$ \\
\hline $\begin{array}{l}\text { N. heterophyllum } \\
\text { C. hirsuta }\end{array}$ & $\begin{array}{c}31.63 \mathrm{a} \\
40.0 \mathrm{a}\end{array}$ \\
\hline
\end{tabular}
${ }^{1)}$ Percentage of emergence was calculated based on the number of diamondback moth larvae used. Means in the same column followed by a common letter were not significantly different $(P=0.05)$, using Least Significant Difference test; data were transformed to arcsin $\mathrm{x}$ before analysis; each value in the table is an average of eight replications.

\section{Occurrence of $D$. eucerophaga on $N$. heterophyllum, C. hirsuta and B. oleracea var. capitata in the field}

The average number of $D$. eucerophaga adults emerging from its host collected from three host plant habitats is shown in Table 5.

The number of $D$. eucerophaga adults which emerged from its host feeding on three cruciferous plants did not differ significantly from each other, although

Table 5. Average numbers of D. eucerophaga adults emerged from its host collected from three cruciferous plant habitats

\begin{tabular}{lc}
\hline Plant habitats & $\begin{array}{c}\text { Average number of } \\
\text { parasitoids emerged }{ }^{1)}\end{array}$ \\
\hline$N$. heterophyllum & $1.4 \mathrm{a}$ \\
C. hirsuta & $2.4 \mathrm{a}$ \\
B. oleracea & $2.8 \mathrm{a}$ \\
\hline 1) Means in the same column followed by a common letter were not significantly different $(\mathrm{P}=0.05)$, using \\
Least Significant Difference test; data were transformed to $\sqrt{\mathrm{x}}+1$ before analysis; each value in the table is \\
an average of ten replications.
\end{tabular}


cabbage and $C$. hirsuta seemed to provide better habitats than $N$. heterophyllum. The data suggested that in the field, diamondback moths can lay eggs on the wild crucifers, $N$. heterophyllum and C. hirsuta. The larvae of diamondback moths can feed on the wild crucifers aside from cabbage.

\section{Occurrence of D. eucerophaga on TV. heterophyllum, $C$. hirsuta and insecticide-treated $B$. oleracea var capitata in the field}

In Experiment 5, cabbage plots were sprayed with insecticide, while wild crucifers plots were not. The results of Experiment 5 are shown in Table 6.

The average number of $D$. eucerophaga in insecticide-treated cabbage plots was the lowest among the three plant habitats, although it did not differ significantly from that in $N$. heterophyllum habitat. The average number of D. eucerophaga in C. hirsuta habitat was the highest and significantly different from the other two.

Data from Experiment 4 and 5 suggested that there might be a movement of diamondback moths and $D$. eucerophaga parasitoids from insecticide-treated cabbage plots to adjacent wild crucifer plots. Thus, wild crucifers growing in the surrounding of the cabbage field may provide refuge for $D$. eucerophaga parasitoids when unfavourable conditions prevail.

Table 6. Average numbers of D. Eucerophaga adults emerged from its host collected from two wild cruciferous and insecticide-treated cabbage plant habitats

\begin{tabular}{lc}
\hline \hline Plant habitats & $\begin{array}{c}\text { Average number of } \\
\text { parasitoids emerged }\end{array}$ \\
\hline$N$. heterophyllum & $2.3 \mathrm{a}$ \\
C. hirsuta & $3.7 \mathrm{~b}$ \\
$B$. oleracea & $1.7 \mathrm{a}$ \\
(treated with insecticide) & \\
\hline
\end{tabular}

\footnotetext{
${ }^{1)}$ Means in the same column followed by a common letter were not significantly different $(\mathrm{P}=0,05)$, using Least Significant Difference test; data were transormed to $\sqrt{x}+1$ before analysis; each vaue in the table is an average of ten replications
}

The experimental results discussed above provide information on the potential role of wild cruciferous plants in the preservation of D. eucerophaga, a parasitoid of the diamondback moth, $P$. xylostella.

Two species of wild crucifers, TV. heterophyllum and C. hirsuta, can provide oviposition sites for diamondback moths and can serve as larval food. D. eucerophaga parasitoid can survive on its host feeding on the aforementioned wild crucifers. 
P. xylostella is an oligophagous insect feeding on a number of plant species of Cruciferae (Thorsteinson 1952) which contain a secondary compound known as mustard oil glucoside (Thorsteinson 1952; Gupta and Thorsteinson 1960; Harborne 1988). This compound serves both as oviposition and feeding stimulant for the diamond-back moth.

P. xylostella larva is a specific host for D. eucerophaga parasitoids (Vos 1953). Therefore, in order to enhance the survival of the parasitoid under unfavourable conditions, such as during insecticide application or in the absence of cabbage plants in the field, it is necessary to ensure the availability of wild cruciferous plants refuge for the pest residue. This necessity was supported by data from the last experiment. When cabbage plants were treated with insecticide, the diamondback moth in wild crucifers could support the survival of $D$. eucerophaga parasitoids.

The wild crucifer C. hirsuta seems to be more suitable than $N$. heterophyllum as refuge for the diamondback moth and its parasitoid.

\section{ACKNOWLEDGEMENT}

The research work was supported by SEAMEO BIOTROP. The authors wish to thank Prof. Dr.Ir. Amris Makmur for making possible to carry out the experiment and to Prof.Dr.Ir. H. Sitti Soetarmi Tjitrosomo for her guidance and criticism.

\section{REFERENCES}

BACKER, C.A. and D.F. van SLOOTEN. 1924. Javaansche thee onkruiden. Batavia Drukkerijen Ruygrok \& Co. 287 p. EVERAARST, A.P. 1981. Weeds of vegetables in the highlands of Java. Lembaga Penelitian Hortikultura, Pasar Minggu, Jakarta. 121 p. GUPTA, P.D. and A.J.

THORSTEINSON. 1960. Food plant relationship of diamondback moth (Plutella maculipennis Curt.). II. Sensory regulation of oviposition of the adult female. Ent. Exp. Appl. 3: 305-314.

HARBORNE, J.B. 1988. Introduction to Ecological Biochemistry. Academic Press, London. 356 p.

HARCourt, D.G. 1957. Biology of the diamondback moth, Plutella maculipennis Curt. (Lepidoptera: Plutellidae), in Eastern Ontario. II. Life history, behaviour, and host relation-ships. Can. Entomol. 89: 554-564.

LUCKMANN, W.H. and R.L. METCALF. 1975. The pest-management concept. In Introduction to Insect Pest management (R.L. Metcalf and W.H. Luckmann, eds.), p. 3-35. John Wiley \& Sons, New York. 587 p. 
SUDARWOHADI, S. 1984. Status pengendalian hayati hama Plutella xylostella oleh parasitoid Diadegma eucerophaga di Jawa Barat. Seminar Hama dan Penyakit Sayuran di Cipanas, 29-30 Mei 1984. 17 p.

THORSTEINSON, A.J. 1952. The chemoctactic responses that determine host specificity in an oligophagous insect (Plutella maculipennis Curt., Lepidoptera). Can. J. Zool. 31: 52-72.

VANDEN BOSCH, R. and A.D. TELFORD. 1973. Environmental modification and biological control. In Biological Control of Insect Pests and Weeds (P. DeBach, ed.): 459-488. Chapman and Hall, Ltd., London. 844 p. VAN EMDEN, H.F. 1976. Pest Control and its ecology. Edward Arnold. 59 p.

vos, H.C.A.A. 1953. Introduction in Indonesia of Angitia cerophaga Grav., a parasite of Plutella maculipennis Curt. Cont. Gen Agric. Res. Stat., Bogor. 32 p. 